\title{
Breastfeeding Can Reduce the Risk of Developing Diabetes
}

\author{
Soo Young Kim* \\ Department of Family Medicine, Kangdong Sacred Heart Hospital, Hallym University College of Medicine, Seoul, Korea
}

\section{See original paper on $\mathbf{2 7 3}$}

It is well known that breastfeeding has a positive effect on neonate health, including cognitive development, emotional stability, and growth. Breastfeeding also has important benefits for the health of the mother and may reduce the risk of chronic diseases, such as hypertension, hyperlipidemia, and breast and ovarian cancer. ${ }^{1)}$

It has recently been suggested that breastfeeding also reduces the risk of maternal diabetes. The relationship between breastfeeding and maternal diabetes incidence is related to both breastfeeding itself, ${ }^{2)}$ and to the duration of breastfeeding. ${ }^{3)}$ This association was still positive after adjustment for pre-pregnancy obesity, gestational metabolism, perinatal outcomes, sociodemographic factors, and post-delivery lifestyle behavior. ${ }^{4)}$ The results of follow-up for more than 30 years have recently been published, and the duration of breastfeeding and risk of diabetes were significantly associated. ${ }^{5)}$

In the present issue, Kim et al. ${ }^{6)}$ evaluated the association between breastfeeding and the prevalence of diabetes in Korean parous women using the 5th-6th Korea National Health and Nutrition Examination Survey data. After adjustment for age, body mass index, education level, income, and other variables, the authors found that the prevalence of diabetes was significantly lower in women who had breastfed than in those who had not, with an odds ratio of 0.534 (95\% confidence interval [CI], 0.289-0.976) in women who breastfed for 0-6 months and 0.575 (95\% CI, 0.321-0.990) in women who breastfed for 6-12 months. These results are similar to findings in a previous systematic review that reported a lower odds ratio among those subjects who had breastfed (pooled odds ratio, 0.65 ; 95\% CI, 0.49-0.86). ${ }^{7)}$

According to the Korean National Commission for United
Nations International Children's Emergency Fund report on breastfeeding in 2016, 18.3\% of Koreans met the World Health Organization recommended full breastfeeding duration of up to 6 months after birth, in contrast to the international average of $40 \%{ }^{8}{ }^{8}$ Mothers should be encouraged to exclusively breastfeed all their infants for at least 6 months.

\section{CONFLICT OF INTEREST}

No potential conflict of interest relevant to this article was reported.

\section{REFERENCES}

1. Turck D; Comite de nutrition de la Societe francaise de pediatrie. Breast feeding: health benefits for child and mother. Arch Pediatr 2005;12 Suppl 3:S145-65.

2. Zhang BZ, Zhang HY, Liu HH, Li HJ, Wang JS. Breastfeeding and maternal hypertension and diabetes: a population-based cross-sectional study. Breastfeed Med 2015;10:163-7.

3. Villegas R, Gao YT, Yang G, Li HL, Elasy T, Zheng W, et al. Duration of breast-feeding and the incidence of type 2 diabetes mellitus in the Shanghai Women's Health Study. Diabetologia 2008;51:258-66.

4. Gunderson EP, Hurston SR, Ning X, Lo JC, Crites Y, Walton D, et al. Lactation and progression to type 2 diabetes mellitus after gestational diabetes mellitus: a prospective cohort study. Ann Intern Med 2015;163:889-98.

5. Gunderson EP, Lewis CE, Lin Y, Sorel M, Gross M, Sidney S, et al. Lactation duration and progression to diabetes in women across the childbearing years: the 30-year CARDIA study. JAMA Intern Med 2018;178:328-37.

6. Kim HN, Jung YA, Kang LL, Park HK, Hwang HS, Park KY. Association between breastfeeding and prevalence of diabetes in Korean parous women: the Korea National Health and Nu-

*Corresponding Author: Soo Young Kim https://orcid.org/0000-0002-3205-9408

Tel: +82-2-2224-2406, Fax: +82-2-2224-2409, E-mail: hallymfm@gmail.com 
trition Examination Survey, 2010-2014. Korean J Fam Med 2018;39:273-8.

7. Horta BL, Loret de Mola C, Victora CG. Long-term consequences of breastfeeding on cholesterol, obesity, systolic blood pressure and type 2 diabetes: a systematic review and meta-analysis. Acta Paediatr
2015;104:30-7.

8. Choi EJ, Park EJ, Kim HR, Oh MA, Lee NH, Choi JH. Survey on breastfeeding in Korea. Sejong: Korea Institute for Health and Social Affairs; 2016. 